\title{
Research Article \\ Gender Disparity in Health and Food Expenditure in India among Elderly
}

\author{
Barsharani Maharana ${ }^{1}$ and Laishram Ladusingh ${ }^{2}$ \\ ${ }^{1}$ International Institute for Population Sciences, Govandi Station Road, Deonar, Mumbai, Maharashtra 400 088, India \\ ${ }^{2}$ Department of Mathematical Demography \& Statistics, International Institute for Population Sciences, \\ Govandi Station Road, Deonar, Mumbai, Maharashtra 400 088, India
}

Correspondence should be addressed to Barsharani Maharana; barsha.iips@gmail.com

Received 9 April 2014; Accepted 5 August 2014; Published 27 August 2014

Academic Editor: Mzikazi Nduna

Copyright (C) 2014 B. Maharana and L. Ladusingh. This is an open access article distributed under the Creative Commons Attribution License, which permits unrestricted use, distribution, and reproduction in any medium, provided the original work is properly cited.

\begin{abstract}
The present paper aims to shed light on the changing pattern of gender disparity in health and food expenditure over time among the elderly in India. National Sample Survey Organization (NSSO) data of the 55th (1999-2000) and the 64th (2007-2008) rounds on household consumer expenditure have been used for this study. Further, the paper examines whether change in the sex composition of the elderly in households contributes to a change in health and food expenditure. The findings indicate wide gender disparity in food and health care expenditure, with that of males being higher than that of their female counterparts; the gap, however, is narrowing with time. The compositional shift in sex among the elderly in households contributes significantly to the decline in household health and the increase in household food expenditure over time.
\end{abstract}

\section{Introduction}

The age of an individual is an important factor when it comes to economic and demographic behaviour, health care needs, food habits, and consumption of goods and services. As individuals move through the lifecycle, chronological age changes and so does the need for different goods and services, test for different commodities, and health care. More important, in the course of lifecycle the economic status of an individual changes from being the bread winner to being dependent on others. Some of these changes have inertia towards improvement with the progress of development, while others, such as health care cost, are irreversible and can even intensify. The inherent influence of age on the various aspects of an individual's life has tremendous implications for health care and food expenditure, more so with the changing household age and sex composition resulting from the demographic transition. Household age-sex composition also determines the pattern of intrahousehold allocation of expenditure. It has been suggested that in any study of consumer behaviour, factors like education, age, region, occupation, and so forth should be included in the demand function [1]. With the change in age and sex distribution, consumption of goods and services is also changing which has a significant impact on a nation's economic growth [2-4]. Keeping the foregoing discussion in view, this paper makes an attempt to shed light on the changing pattern of health care and food expenditure of the elderly in India from 19992000 to 2007-2008. An important accompanying objective of the paper is to measure and quantify the gender gap in household health care and food expenditure of the elderly and to examine whether the gap is narrowing with time or not. The study is pertinent in the Indian context for two main reasons. First, the average household size has declined over time, with the traditional extended joint family system making way for nuclear families and the elderly population increasing gradually. Secondly, though the life expectancy of women has overtaken that of men, gender role in the Indian society has not changed enough to prevent the discrimination against women even from food and health care rights. 


\section{Review of the Literature}

Lin [5] highlights the linkage between changing consumption levels and pattern of commodities consumption with changing economic and demographic factors using the 1961 Philippines household survey. The study shows the household size, rural to urban migration, and the household budget as the most important factors in explaining changing consumption levels, accounting for about 72 to 79 percent of incremental food expenditure and about 61 to 64 percent of incremental nonfood expenditure. Huang and Raunikar [6] study the effect of variation in household age sex composition on food expenditure and conclude that food expenditure among the youngest children is substantially lower than among the adults.

Seshamani and Gray [7] using a multicountry study which includes England and Wales, Canada, Japan, and Australia show the extent to which changes in population growth, demographic shift, and changes in age pattern contribute to changing health expenditure. Demery and Duck [8] use family expenditure survey, an annual cross-sectional survey of around 7,000 UK households, to analyze the association between consumption behaviour and age structure of households for 30 consecutive calendar years (1969-1993). They conclude that household data exaggerate savings rates of young adults and the elderly whilst underestimating those of 45 to 60 years old, and individual saving rates follow more closely the "hump shape" of the life-cycle model, although the savings rates of the elderly remain positive for some ages. Dormont et al. [9] use microdata of 1992 and 2000 for France to justify that individual health care expenditure is an increasing function of age. Utilising data from the 1987 National Medical Expenditure Survey (NMES) and the 1996 Medical Expenditure Panel Survey (MEPS), Selden and Banthin [10] have found that health care expenditure is high and is a burden for the old age people. Analysing Norwegian quarterly time series data, Erlandsen and Nymoen [11] have found that changes in the age distribution of the population have significant and lifecycle consistent effects on aggregate consumption. As regards the association between age composition and health care expenditure, Lubitz and Riley [12] have found that health care costs for persons in their last year of life reach a maximum at about the age of 70 years and fall thereafter. Fuchs [13], for the first time, points out the fact that the health care utilization cost for persons in their last years of life is higher than the average health care cost and increases rapidly with age. Ladusingh and Pandey [14] too have found higher inpatient care costs for decedents than that of survivors in India. In addition to the trends in the composition of household expenditure over time, analysing expenditure differences on the basis of household characteristics of Australia, The Productivity Commission [15] has found that an ageing population is likely to result in increased consumption of goods and services favoured by the older age groups. They have also shown that medical care, health expenses, and sharing of food are increasing for the elderly. Using the Health and Retirement Study (HRS) data, Banerjee [16] has analysed the change in the pattern of expenditure of the American elderly and found that health related expenses are the largest component in the budget of older Americans and is the only component which steadily increases with age. Mirel and Carper [17] have analysed the Medical Expenditure Panel Survey Household (MEPS-HC) and Medical Provider Components (MEPS-MPC) data on the US civilian noninstitutionalized population for the years 2001, 2006, and 2011 and found that the average annual expenditure per elderly person was about $\$ 1,000$ higher in 2011 than 2001. Newhouse [18] assesses the relative importance of ageing in the increase in health expenditures per capita during the period from 1940 to 1990 in the United States. He finds that ageing, in the sense of an increasing proportion of population in the 65-plus age group, holding constant age-specific health expenditures, explained 2 percent of the increase per capita health spending during this period, a result confirmed by Cutler [19]. Using the consumption expenditure data, National Sample Survey, 2009-10, Mohanty et al. [20] have tested the hypothesis that the monthly per capita household health spending of the elderly households is significantly higher than that of the nonelderly households in India and concluded that the monthly per capita health spending of the elderly households is 3.8 times higher than that of the nonelderly households.

Elderly women in India face various socioeconomic, environmental, psychological, and health related issues due to their increased vulnerability, as they are more likely to be widowed and have low economic security, lower educational attainment, less labour force experience, and more care giving responsibilities (WHO [21]). Sen et al. [22] have analysed India's National Sample Survey data for 1986-1987 and 1995-1996 to study the change in health inequality by gender and have found that gender inequity, particularly in untreated morbidity and health care cost, continued to be severe. Ostlin et al. [23] analyse mortality, morbidity, health care, and clinical health research on both the high and low income countries like Mali, Bolivia, India, South Africa, Egypt, China, Poland, and Sweden and conclude that gender acts as an important determinant of health inequalities and inequity. Cameron et al. [24] analyse national data on 9164 representative elderly Americans to investigate gender differences in the use of healthcare and the extent to which any observed gender differences were mediated by differential health needs and economic access and find that health needs were substantially greater among older women compared with older men and that women had fewer economic resources. Batra et al. [25] use a longitudinal survey on rural patients suffering from cancer in a public tertiary health centre in Odisha and investigated if there are gender differences in health expenditures and treatment seeking behaviour among adults, focusing on the role of gender discrimination in explaining these differences. They conclude that expenditures on female adults are significantly lower than those on males. Rout [26] studies the collected data of 120 households from urban Odisha to assess the gender difference in health expenditure and shows that there is a significant difference between male and female out-of-pocket health expenditure in urban areas. An integrative review to explore issues faced by ageing women [27] suggests that 
women continue to face inequities related to health care, often invisible within the discourse of the ageing policy.

On the other hand, gender also plays the main role in intrahousehold food allocation. Lancaster et al. [28] use the 50 th round of the National Sample Survey data of India for three states, namely, Kerala, Bihar, and Maharashtra, to examine the gender difference in expenditure allocation, and find that it is more prevalent in the adult age group. They conclude that, in Maharashtra, increase in the proportion of male adults leads to a strong and significant increase in the budget share of food, whereas that in female adults leads to a statistically significant decline, thus providing a strong example of promale gender bias in food spending in Maharashtra. According to a study conducted by Nesbitt et al. [29] in Canada, consumption of many food items varies by gender and age and specific foods are significantly more likely to be consumed by the elderly male individuals.

From the foregoing discussion, it is noted that sporadic attempts have been made to find the changing pattern of household expenditure on health care and food in India and that the few available studies are far from complete. The present study is an attempt to fill this research gap and provide empirical evidence on the extent of gender discrimination in health care and food expenditure among the elderly in India. As emphasized in the preceding paragraphs, the study is also important as in India with the changing pattern of population growth the age and sex distribution has also been changing. The specific objectives of the study are to assess the gender disparity in health and food expenditure among the elderly and to examine whether the change in the sex composition of the elderly contributes to changes in health and food expenditure.

\section{Data and Methods}

3.1. Data. The data used in this study consists of 42,747 and 19,547 elderly population of 60 years and above from the 55th round (1999-2000) and the 64th round (2007-2008) of the National Sample Survey Organization (NSSO) on household consumer expenditure. It is a nationally representative household survey and, from each household, expenditure on food items and nonfood items was collected for the last thirty days. Expenditure on education was collected for a reference period of one year. Items of expenditure on institutional health care include medicine, X-ray, ECG, pathological test, doctor's/surgeon's fee, hospital and nursing home charges, and other medical expenses that were collected for a reference period of one year but for noninstitutional health care expenditure; the reference period is the last 30 days. Further, for each household member, details about age, sex, marital status, educational level, and occupation were also collected. The sampling designs adopted in both rounds of NSSO surveys were multistratified sampling and were comparable.

3.2. Methods. Descriptive statistics and bivariate analysis are used to describe the characteristics of elderly and to assess whether gender disparity exists in food and health expenditure. Household expenditure on food is first allocated to household members by age using regression approach. As for the allocation of household health expenditure to individual members by age a cubic polynomial regression is adopted.

Gender inequality in the distribution of household health and food expenditure among elderly is measured with the Theil decomposition indices [30]. The Theil index's main attraction lies in its decomposability that estimates the contribution of different groups to total inequality [31].

The Theil index is given by

$$
\begin{aligned}
T & =\sum_{i=1}^{m} \sum_{j=1}^{n_{i}}\left(\frac{y_{i j}}{Y}\right) \log \left(\frac{y_{i j} / Y}{1 / n}\right) \\
& =\frac{1}{n} \sum_{i=1}^{m} \sum_{j=1}^{n_{i}}\left(\frac{y_{i j}}{\mu}\right) \log \left(\frac{y_{i j}}{\mu}\right),
\end{aligned}
$$

where $m=$ total population in all households; $y_{i j}=$ per capita expenditure of household $j$ in group $i(i=1,2, \ldots, m ; j=$ $\left.1,2, \ldots, n_{i}\right) ; n_{i}=$ total number of households in group $i(i=$ $1,2, \ldots, m) ; Y=\left(\sum_{i=1}^{m} \sum_{j=1}^{n_{i}} y_{i j}\right)=$ total expenditure of all households; $n=\left(\sum_{i=1}^{m} n_{i}\right)=$ total number of all households; and $\mu=(Y / n)=$ mean per capita expenditure for all households.

Following [19] Theil index $T$ is decomposed into withinsex component and between-sex component as follows:

$$
T=\sum_{i=1}^{m}\left(\frac{Y_{i}}{Y}\right) T_{i}+\sum_{i=1}^{m}\left(\frac{Y_{i}}{Y}\right) \log \left(\frac{Y_{i} / Y}{n_{i} / n}\right)=T_{w}+T_{B}
$$

where $Y_{i}=$ total expenditure of households in group $i$ and $n_{i}=$ total number of households in group $i$.

Theil index $L$ is given by

$$
L=\sum_{i=1}^{m} \sum_{j=1}^{n_{i}}\left(\frac{1}{n}\right) \log \left(\frac{1 / n}{y_{i j} / Y}\right)=\frac{1}{n} \sum_{i=1}^{m} \sum_{j=1}^{n_{i}} \log \left(\frac{\mu}{y_{i j}}\right) .
$$

This index can also be decomposed additively into the withinsex component and the between-sex component as given in the following [32]:

$$
L=\sum_{i=1}^{m}\left(\frac{n_{i}}{n}\right) L_{i}+\sum_{i=1}^{m}\left(\frac{n_{i}}{n}\right) \log \left(\frac{n_{i} / n}{Y_{i} / Y}\right)=L_{W}+L_{B}
$$

A multivariate decomposition analysis by Martin and Njogu [33] is used to study whether the shift in demographic composition has made significant contribution to overall change in expenditure. The decomposition procedure applied in this study is based on the logit models estimated for the two surveys. The difference $\ln [p /(1-p)]_{\mathrm{NSSO} 2007-08}-$ 
$\ln [p /(1-p)]_{\mathrm{NSSO} 1999-00}$ is decomposed using the following equation:

$$
\begin{aligned}
\operatorname{logit} & (\mathrm{NSSO})_{2007-08}-\operatorname{logit}(\mathrm{NSSO})_{1999-00} \\
= & \left(\beta_{02007-08}-\beta_{01999-00}\right) \\
& +\sum P_{i j_{1999-00}}\left(\beta_{i j_{2007-08}}-\beta_{i j_{1999-00}}\right) \\
& +\sum \beta_{i j_{1999-00}}\left(P_{i j_{2007-08}}-P_{i j_{1999-00}}\right) \\
& +\sum\left(P_{i j_{2007-08}}-P_{i j_{1999-00}}\right)\left(\beta_{i j_{2007-08}}-\beta_{i j_{1999-00}}\right)
\end{aligned}
$$

where $p$ is the probability of occurrence of the event, $\beta_{01999-00}$ is the regression constant in $\mathrm{NSSO}_{1999-00}, \beta_{02007-08}$ is the regression constant in $\mathrm{NSSO}_{2007-08}, P_{i j_{1999-00}}$ is the proportion of $j$ th category in $i$ th covariate in $\mathrm{NSSO}_{1999-00}, P_{i j_{2007-08}}$ is the proportion of $j$ th category in $i$ th covariate in $\mathrm{NSSO}_{2007-08}$, $\beta_{i j_{1999-00}}$ is the coefficient of $j$ th category of the $i$ th covariate in $\mathrm{NSSO}_{1999-00}$, and $\beta_{i j_{2007-08}}$ is the coefficient of $j$ th category of the $i$ th covariate in $\mathrm{NSSO}_{2007-08}$.

This procedure gives three components, namely, rate, composition, and interaction. Rate reflects the differences in regression coefficients and intercept, the composition component indicates the proportion of overall change attributable to the variation in the means of the covariates, and the interaction alludes to the covariation between the means and the coefficients in the two time periods.

\section{Results}

The findings reveal that the distribution of the elderly population has increased over time from 7.13 percent to 8.06 percent, with the increase in the elderly female population being due to an increase in life expectancy among women in India. The changes in the household expenditure and the expenditure by the elderly aged 60 years and above on food, nonfood, health, and education between 1999-2000 and 2007-2008 are shown in Table 1. In 1999-2000, the household expenditure on nonfood items was 40 percent, whereas it has increased by 26 percent in 2007-2008. On the contrary, household food expenditure has declined from 59.2 to 31.9 percent during this time period. Household expenditure on education was 0.3 percent in 1999-2000 and has increased to 5.9 percent in 2007-2008, which is considered to be significant. Virtually, household expenditure on health care is negligible compared to expenditure on other food and nonfood items, and it has not improved over time. When it comes to expenditure by the elderly aged 60 years and above, the share of expenditure on food has declined from 39.5 to 25.8 percent from $1999-2000$ to $2007-2008$, while that on nonfood items has increased over time from 59.6 to 69.2 percent. Contrary to the anticipated rising health care cost with age over time, health care expenditure by the elderly is not even one percent of the total expenditure.

The gender gap in expenditures on food and health care of the elderly in 1999-2000 and 2007-2008 is shown in Figures 1 and 2, respectively. As regards the expenditure on food

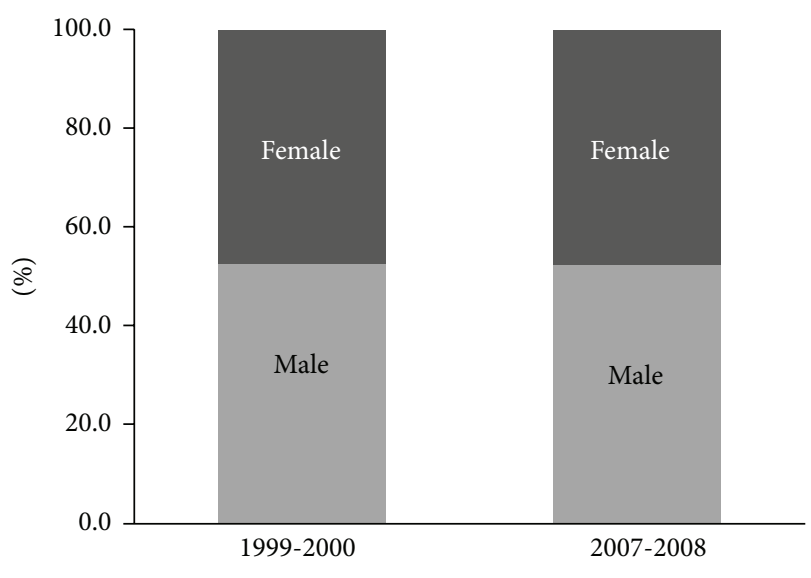

FIGURE 1: Gender differences in food expenditure among the elderly in India.

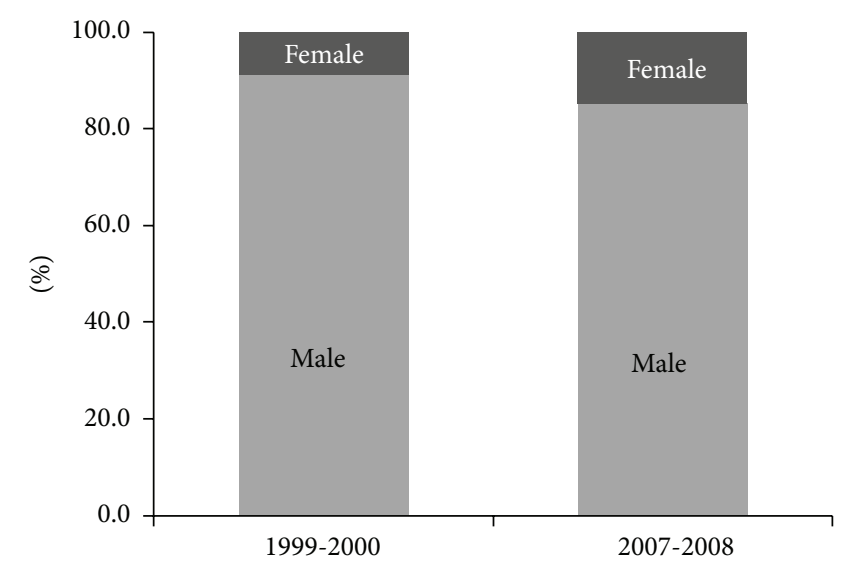

FIGURE 2: Gender differences in health expenditure among the elderly in India.

by the elderly, the gender gap is marginally in favour of males regardless of time. However, there is a wide disparity between the male and the female elderly. Out of the total health expenditure on the elderly, 91.2 percent was spent on males and 8.8 percent on females in 1999-2000. In 20072008, the health expenditure on the elderly females was 6 percent higher than in the first survey period, but the differences between males and females at the two time points are significant.

The share of household health expenditure and that of the elderly aged 60 years and above by items for 1999-2000 and 2007-2008 are shown in Table 2, together with item-wise ratios of male to female expenditure as a measure of gender disparity on health expenditure among the elderly. The major share of the household health expenditure goes towards medicines, constituting 73.4 and 77.7 percent of the total in 1999-2000 and 2007-2008, respectively, indicating a marginal increase over time. Doctor/surgeon's fee for treatment is the next item of the household health expenditure, making up 13.4 and 10.8 percent of the total, at the two time points. The marginal decline is attributed to the improvement in the doctor population ratio over time. Similarly, the substantial 
TABLE 1: Components of household expenditure in India in 1999-2000 and 2007-2008.

\begin{tabular}{lcccc}
\hline Components & \multicolumn{2}{c}{ Household expenditure (percent) } & \multicolumn{2}{c}{ Household expenditure on elderly (percent) } \\
& $1999-2000$ & $2007-2008$ & $1999-2000$ & $2007-2008$ \\
\hline Food & 59.2 & 27.3 & 39.5 & 25.8 \\
Nonfood & 40.1 & 66.2 & 59.6 & 69.2 \\
Health & 0.5 & 0.6 & 0.7 & 0.8 \\
Education & 0.3 & 5.9 & 0.2 & 4.2 \\
\hline Total & 100 & 100 & 100 & 100 \\
\hline
\end{tabular}

TABLE 2: Household expenditure and gender differences on different health items among the elderly at two points of time (1999-2000 and 2007-2008).

\begin{tabular}{|c|c|c|c|c|c|c|}
\hline \multirow[t]{2}{*}{ Health items } & \multicolumn{2}{|c|}{$\begin{array}{c}\text { Item-wise household } \\
\text { expenditure for healthcare } \\
\text { (percent) }\end{array}$} & \multicolumn{2}{|c|}{$\begin{array}{c}\text { Item-wise share of household } \\
\text { expenditure for elderly } \\
\text { healthcare (percent) }\end{array}$} & \multicolumn{2}{|c|}{$\begin{array}{c}\text { Gender differences in item-wise } \\
\text { expenditure for elderly } \\
\text { healthcare (male-female ratio) }\end{array}$} \\
\hline & $1999-2000$ & 2007-2008 & $1999-2000$ & 2007-2008 & $1999-2000$ & $2007-2008$ \\
\hline Medicine & 73.4 & 77.7 & 25.3 & 25.1 & 13.3 & 5.3 \\
\hline $\begin{array}{l}\text { X-ray, ECG, pathological } \\
\text { test, and so forth }\end{array}$ & 5.9 & 5.4 & 7.2 & 31.4 & 2.6 & 2.8 \\
\hline Doctor/surgeon's fee & 13.4 & 10.8 & 46.0 & 20.6 & 28.6 & 8.5 \\
\hline $\begin{array}{l}\text { Hospital and nursing } \\
\text { home charges }\end{array}$ & 3.2 & 0.7 & 35.7 & 24.1 & 16.8 & 10.6 \\
\hline Other medical expenses & 4.1 & 5.3 & 5.5 & 26.1 & 25.6 & 21.1 \\
\hline
\end{tabular}

decrease in expenditure on hospital and nursing home charges from 3.2 to 0.7 percent during 1999-2008 is due to the expansion of health system in India. About 6 percent of the household health expenditure is for X-ray, ECG, pathological tests, and so forth, while 4 to 5 percent is for other expenses. The patterns of expenditure on different items of health care for the elderly aged 60 years and above are distinct from that of household health expenditure. For the elderly, health care expenditure on clinical examination, including X-ray, ECG, and pathological tests, has increased from 7.2 percent in 19992000 to 31.4 percent in 2007-08, while other medical expenses have escalated from 5.5 to 26.1 percent during 1999-2008. However, similar to the pattern of household health care, of the total health care expenditure of the elderly during 19992008, spending on doctor/surgeon's fee has reduced from 46 to 20.6 percent and that on hospital and nursing home charges has reduced from 35.7 to 24.1 percent. The share of expenditure on medicines remains stable at 25 percent of the total. The last two columns of Table 2 show ratios of male to female expenditure for the different items of health care for 1999-2000 and 2007-2008.

It is evident from Figures 3 and 4 that, in all the regions and for both the surveys, a higher amount is spent on elderly males for health and food than on elderly females. It is observed that there is a substantial increase in health expenditure on the females from the first to the second survey period in all the regions. In the northern and the southern regions, health expenditure on the elderly female is comparatively higher than all the regions according to both surveys. However, the gender difference in health expenditure is noticeable among the elderly in all the regions.

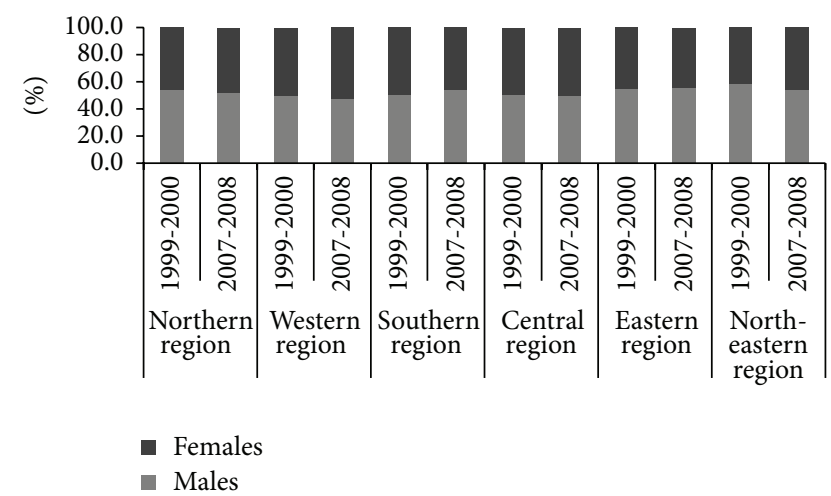

FIGURE 3: Gender differences in food expenditure among the elderly in different regions of India at two points of time.

4.1. Result of Decomposition Analysis. Table 3 reflects the between group component explaining 4 percent of the total inequality by the Theil $L$ index, which indicates that gender is an important factor behind explaining inequality in health expenditure for the period 1999-2000. However, for the period 2007-2008, the between group contribution to the total inequality is marginal, whereas the higher Gini index measure of 7.02 for the elderly females indicates higher within group inequality in health expenditure as compared to males. The between group contributions to total inequality by the Theil indices (Table 4) indicate that gender is not an important factor behind explaining total inequality in food expenditure according to both surveys. Nevertheless, 
TABLE 3: Inequality decomposition by gender among elderly, India (health expenditure).

\begin{tabular}{|c|c|c|c|c|c|c|c|c|}
\hline \multirow{2}{*}{ Gender } & \multicolumn{4}{|c|}{$1999-2000$} & \multicolumn{4}{|c|}{$2007-2008$} \\
\hline & Theil T & Theil L & $\mathrm{GE}(-1)$ & Gini & Theil T & Theil L & $\mathrm{GE}(-1)$ & Gini \\
\hline Male & 0.585 & 0.658 & 1.524 & 0.572 & 0.832 & 0.807 & 1.651 & 0.642 \\
\hline Female & 0.401 & 0.454 & 0.786 & 0.468 & 1.043 & 1.115 & 2.866 & 0.702 \\
\hline All groups & 0.586 & 0.644 & 1.404 & 0.569 & 0.868 & 0.863 & 1.888 & 0.656 \\
\hline Within group & 0.564 & 0.618 & 1.374 & & 0.867 & 0.862 & 1.887 & \\
\hline$\%$ share & 96.2 & 96.0 & 97.9 & & 99.9 & 99.9 & 99.9 & \\
\hline Between group & 0.022 & 0.026 & 0.030 & & 0.001 & 0.001 & 0.001 & \\
\hline$\%$ share & 3.8 & 4.0 & 2.1 & & 0.1 & 0.1 & 0.1 & \\
\hline
\end{tabular}

TABLE 4: Inequality decomposition by gender among elderly, India (food expenditure).

\begin{tabular}{|c|c|c|c|c|c|c|c|c|}
\hline \multirow{2}{*}{ Gender } & \multicolumn{4}{|c|}{ 1999-2000 } & \multicolumn{4}{|c|}{$2007-2008$} \\
\hline & Theil $\mathrm{T}$ & Theil L & $\mathrm{GE}(-1)$ & Gini & Theil $\mathrm{T}$ & Theil L & $\mathrm{GE}(-1)$ & Gini \\
\hline Male & 0.100 & 0.095 & 0.099 & 0.241 & 0.103 & 0.096 & 0.099 & 0.242 \\
\hline Female & 0.087 & 0.084 & 0.090 & 0.228 & 0.094 & 0.088 & 0.091 & 0.235 \\
\hline All & 0.094 & 0.090 & 0.095 & 0.235 & 0.099 & 0.092 & 0.096 & 0.239 \\
\hline Within group & 0.094 & 0.090 & 0.095 & & 0.099 & 0.092 & 0.095 & \\
\hline$\%$ share & 99.7 & 99.7 & 99.7 & & 95.4 & 96.2 & 95.9 & \\
\hline Between group & 0.000 & 0.000 & 0.000 & & 0.001 & 0.001 & 0.001 & \\
\hline$\%$ share & 0.3 & 0.3 & 0.3 & & 0.5 & 0.6 & 0.6 & \\
\hline
\end{tabular}

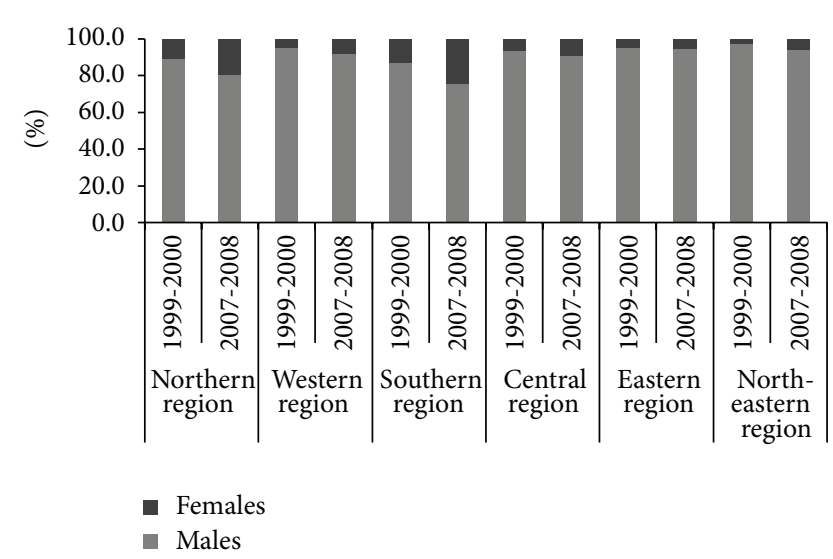

FIGURE 4: Gender differences in health expenditure among elderly in different regions of India at two points of time.

the between group contributions to total inequality have increased from 0.3 percent to 0.6 percent by the Theil $L$ indices.

The results of the multivariate decomposition analysis are presented in Table 5 in terms of magnitude and direction of change associated with the covariates included in the study, namely, age, sex, education, caste, and marital status. The change in the direction in the rates shows a declining trend among different subgroups with respect to the respective reference categories. In case of food expenditure we can see that for age and sex the sign of rate is negative. It means that food expenditure decreases with the increase in age, and food expenditure among females is less than among males. Similarly, in case of health expenditure, the sign of rate is negative for age and sex, which shows that the elderly, particularly the women, are deprived of health facilities. Change in the composition refers to the structural change in the population. Again the result depicts whether the shift in the socioeconomic and demographic composition has made a significant contribution to overall change in food and health expenditure. The table shows that with compositional change in age, that is, with increase in the proportion of the elderly population, the food expenditure has increased from 19992000 to 2007-2008. Similarly, increasing sex composition also contributes to increase in food expenditure. Likewise, improvement in education also has a significant impact on food expenditure. The table reveals that with increase in composition of the elderly population, health expenditure is increasing. On the contrary, while the composition of the elderly females has increased from the first to the second survey period, the health expenditure has decreased. However, education and marital status of the elderly have not made a significant impact on the health expenditure.

\section{Summary and Conclusion}

Male and female elderly in households have increased over time. Out of the total household food expenditure less than one-tenth is spent on the elderly. One-fifth of the total household health expenditure is spent on the elderly in 1999-2000. However, in 2007-2008, one-third of the total household health expenditure is spent on them. Food expenditure on the elderly has decreased over time and health expenditure is quite low, basically remaining the same in both points of time. Gender disparity exists in households among elderly in health as well as food expenditure both in 1999-2000 and 
TABLE 5: Decomposition of change in food and health expenditure among the elderly, India, 1999-2000 and 2007-2008.

\begin{tabular}{lccccc}
\hline Background characteristics & Rate & $\begin{array}{c}\text { Food expenditure } \\
\text { Composition }\end{array}$ & Interaction & Rate & $\begin{array}{c}\text { Health expenditure } \\
\text { Composition }\end{array}$ \\
& -0.0100 & 0.0003 & 0.0006 & -0.0231 & 0.0006 \\
Interaction
\end{tabular}

2007-2008. Though the health expenditure on the elderly women has increased from the first to the second survey period, a huge disparity is seen among the elderly men and women. Moreover, gender differences exist among the elderly in expenditure on different health items like medicines, Xray, ECG, pathological tests, doctor/surgeon's fee, hospital and nursing home charges, and other medical expenses. For all health items, expenditure on males is relatively high as compared to females for both time periods. The findings also indicate that in all the regions, though the amount spent on health and food on elderly women has increased over time, the expenditure on the same is moderately high among elderly males. The finding of the Theil decomposition narrates that gender disparity in health expenditure between groups is persistent among the elderly. Also the result shows that as the composition of female population has increased, food expenditure has also increased, but the amount spent on health has decreased from the first to the second survey period. Most of India's health programmes and policies have been focusing on issues like population stabilisation, maternal and child health, and disease control. However, the demographic transition resulting in increasing older population in India gives a prelude to a new set of medical, social, and economic problems that could arise if timely initiative in this direction is not taken by the program managers and policy makers. Most of India's elderly are economically dependent; the cost of treatment is often a burden on the household. Hence, there is a need for expansion of social and community services for older persons, particularly women, and enhancement in their accessibility and use by removing sociocultural, economic, and physical barriers and making the services client oriented and user friendly. Looking at the scenario, government should implement programmes addressing health care facilities and improving the social status of the elderly while paying attention to the females.

\section{Conflict of Interests}

The authors declare that there is no conflict of interests regarding the publication of this paper.

\section{References}

[1] N. S. Iyengar, "Some estimates of engel elasticities based on National Sample Survey Data," Journal of Royal Statistical Society A, vol. 130, pp. 84-101, 1967.
[2] P. W. Gerbens-Leenes, S. Nonhebel, and M. S. Krol, "Food consumption patterns and economic growth. Increasing affluence and the use of natural resources," Appetite, vol. 55, no. 3, pp. 597$608,2010$.

[3] H. Kiymaz, Y. Akbulut, and A. Demir, "Tests of stationarity and cointegration of health care expenditure and gross domestic product: an application to Turkey," European Journal of Health Economics, vol. 7, no. 4, pp. 285-289, 2006.

[4] J. W. Musila and W. Belassi, "The impact of education on economic growth in Uganda: evidence from national sample survey organisation.1998," Morbidity and Treatment of Ailments Report 441, Government of India, Department of Statistics, New Delhi, India, 2004.

[5] N. Lin, "Analysing the instrumental uses of social relations in the context of social structure," Sociological Method and Research, vol. 7, no. 2, pp. 149-166, 1978.

[6] C. Huang and R. Raunikar, "Estimating the effect of household age sex composition on food expenditures," Southern Journal of Agricultural Economics, vol. 10, no. 2, pp. 151-155, 1978.

[7] M. Seshamani and A. Gray, "The impact of ageing on expenditures in the national health service," Age and Ageing, vol. 31, no. 4, pp. 287-294, 2002.

[8] D. Demery and N. W. Duck, "Savings-age profiles in the UK," Journal of Population Economics, vol. 19, no. 3, pp. 521-541, 2006.

[9] B. Dormont, M. Grignon, and H. Huber, "Health expenditure growth: reassessing the threat of ageing," Health Economics, vol. 15, no. 9, pp. 947-963, 2006.

[10] T. M. Selden and J. S. Banthin, "Health care expenditure burdens among elderly adults: 1987 and 1996.," Medical Care, vol. 41, no. 7, pp. III13-III23, 2003.

[11] S. Erlandsen and R. Nymoen, "Consumption and population age structure," Journal of Population Economics, vol. 21, no. 3, pp. 505-520, 2008.

[12] J. D. Lubitz and G. F. Riley, "Trends in Medicare payments in the last year of life," The New England Journal of Medicine, vol. 328, no. 15, pp. 1092-1096, 1993.

[13] V. R. Fuchs, "Though much is taken: reflections on aging, health, and medical care," Milbank Memorial Fund Quarterly, Health and Society, vol. 62, no. 2, pp. 143-166, 1984.

[14] L. Ladusingh and A. Pandey, "A Pandey, High inpatient care cost of dying in India," Journal of Public Health, vol. 21, no. 5, pp. 435443, 2013.

[15] Economy-wide modelling of impacts of COAG reforms', Supplement to Impacts of COAG Reforms, Business Regulation and VET, Research Report, Productivity Commission Australia, 2012, http://www.pc.gov.au/.

[16] S. Banerjee, "Expenditure patterns of older Americans, 20012009.", Employee Benefit Research Institute, no. 368, pp. 1-25, 2012. 
[17] L. B. Mirel and K. Carper, "Trends in Health care expenditures for the elderly, and 65 and over: 2001, 2006, and 2011," Medical Expenditure Panel Survey, Agency for Healthcare Research and Quality, 2014.

[18] J. P. Newhouse, "Medical care costs: how much welfare loss?" The journal of Economic Perspectives, vol. 6, no. 3, pp. 3-21, 1992.

[19] D. Cutler, Technology, Health Costs and the NIH, Harvard University, Cambridge, Mass, USA, 1995.

[20] S. K. Mohanty, R. K. Chauhan, S. Mazumdar, and A. Srivastava, "Out-of-pocket expenditure on health care among elderly and non-elderly households in India," Social Indicators Research, vol. 113, pp. 1137-1157, 2013.

[21] WHO, Active Ageing a Policy Framework, World Health Organization to the Second United Nations World Assembly in Ageing, Madrid, Spain, April 2002.

[22] G. Sen, A. Iyer, and A. George, "Structural reforms and health equity a comparison of NSS surveys, 1986-87 and 1995-96," Economic and Political Weekly, vol. 37, no. 14, pp. 1342-1352, 2002.

[23] P. Ostlin, A. George, and G. Sen, Gender, Health and Equity: The Intersections, Oxford Scholarship Online, 2009.

[24] K. A. Cameron, J. Song, L. M. Manheim, and D. D. Dunlop, "Gender disparities in health and healthcare use among older adults," Journal of Women's Health, vol. 19, no. 9, pp. 1643-1650, 2010.

[25] A. Batra, I. Gupta, and A. Mukhopadhyay, "Does discrimination drive gender differences in health expenditure on adults: evidence from Cancer patients in rural India," Indian Statistical Institute Discussion Paper 14-03, 2014.

[26] H. S. Rout, "Gender inequality in household health expenditure: the case of urban Orissa," Nagarlok, vol. 38, no. 3, pp. 44-48, 2006.

[27] P. M. Davidson, M. DiGiacomo, and S. J. McGrath, "The feminization of aging: how will this impact on health outcomes and services?" Health Care for Women International, vol. 32, no. 12, pp. 1031-1045, 2011.

[28] G. Lancaster, P. Maitra, and R. Ray, "Household expenditure patterns and gender bias: evidence from selected Indian States," Oxford Development Studies, vol. 36, no. 2, pp. 133-157, 2008.

[29] A. Nesbitt, S. Majowicz, R. Finley et al., "Food consumption patterns in the Waterloo Region, Ontario, Canada: a crosssectional telephone survey," BMC Public Health, vol. 8, article $370,2008$.

[30] H. Theil, Economics and Information Theory, North Holland, Amsterdam, The Netherlands, 1967.

[31] G. S. Fields, "Decomposing LDC inequality," Oxford Economic Papers, vol. 31, no. 3, pp. 437-459, 1979.

[32] N. Chowdhury, "Gender inequality in the distribution of household expenditures in Bangladesh: a Theil Decomposition Analysis (1995-96)," BRAC University Journal, vol. 4, no. 2, pp. 17-26, 1995.

[33] T. C. Martin and W. Njogu, "A decade of change in contraceptive behaviour in Latin America: a multivariate decomposition analysis," Population Bulletin of the United Nations, no. 36, pp. 81-109, 1994. 

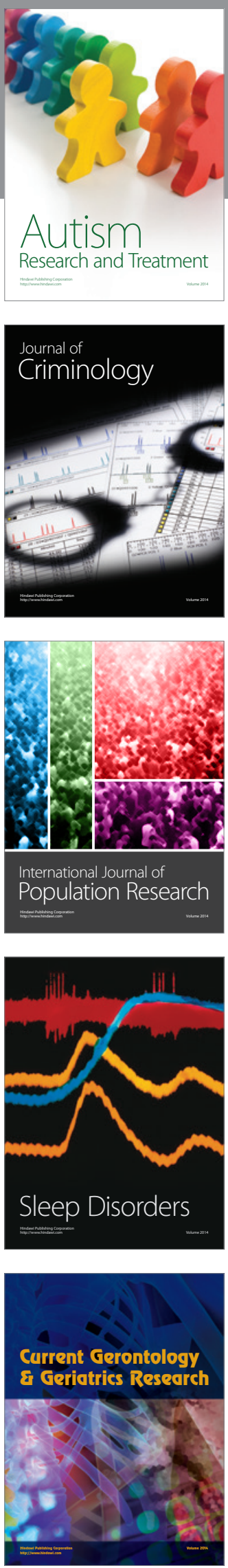
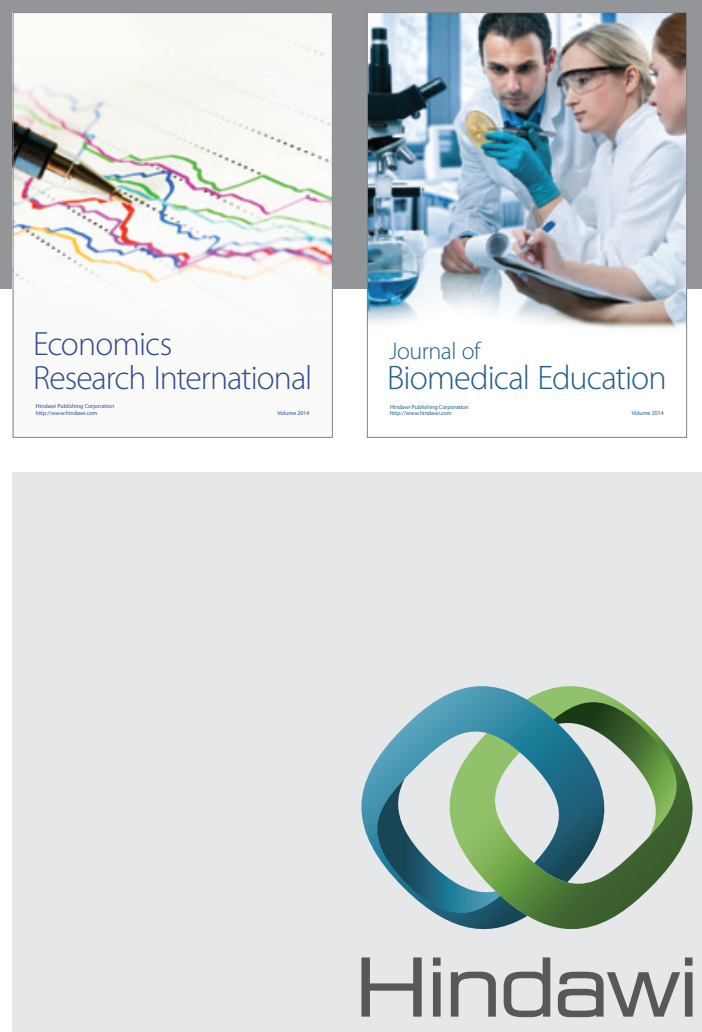

Submit your manuscripts at

http://www.hindawi.com
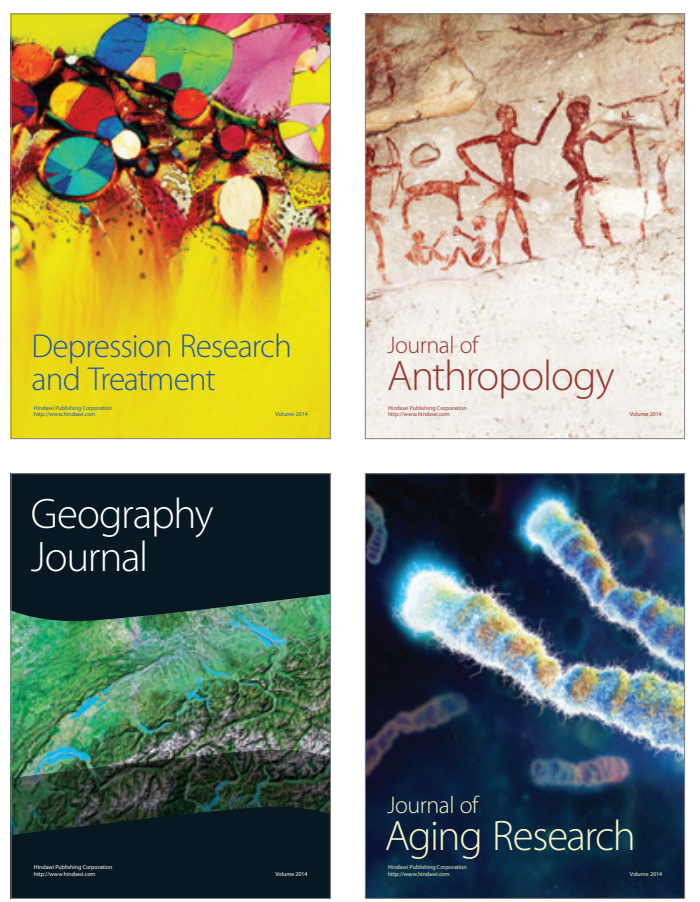
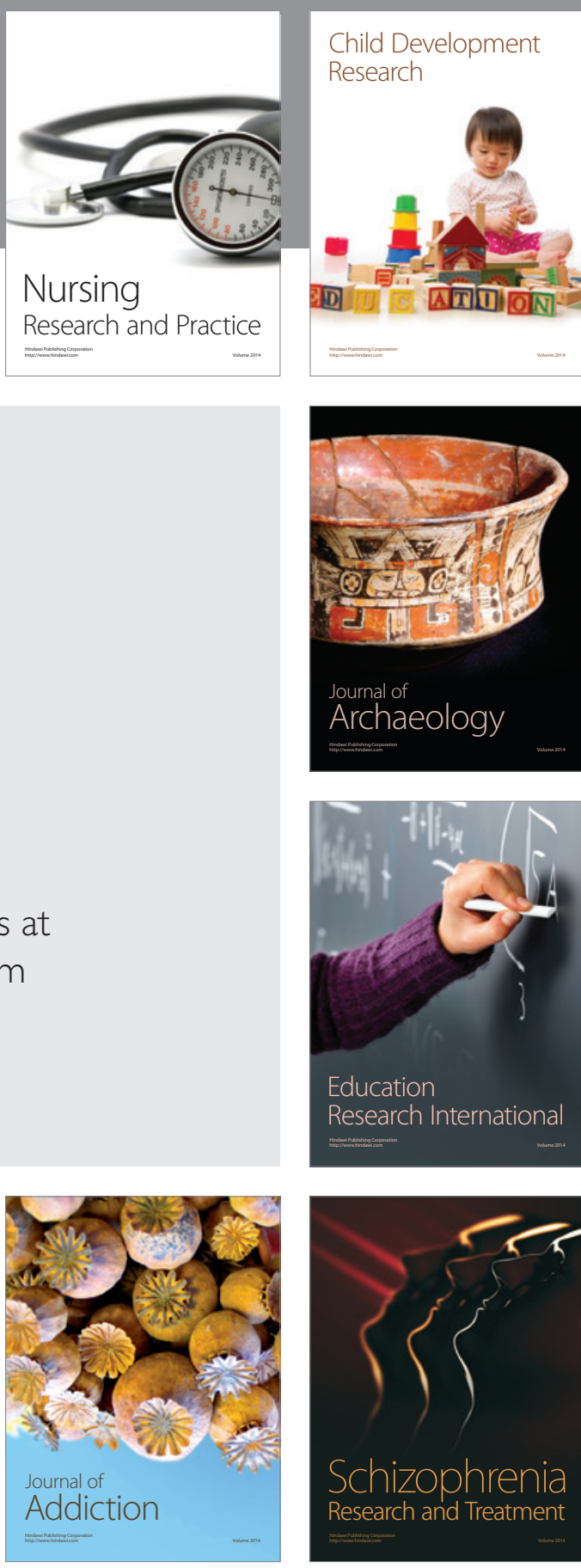

(D)
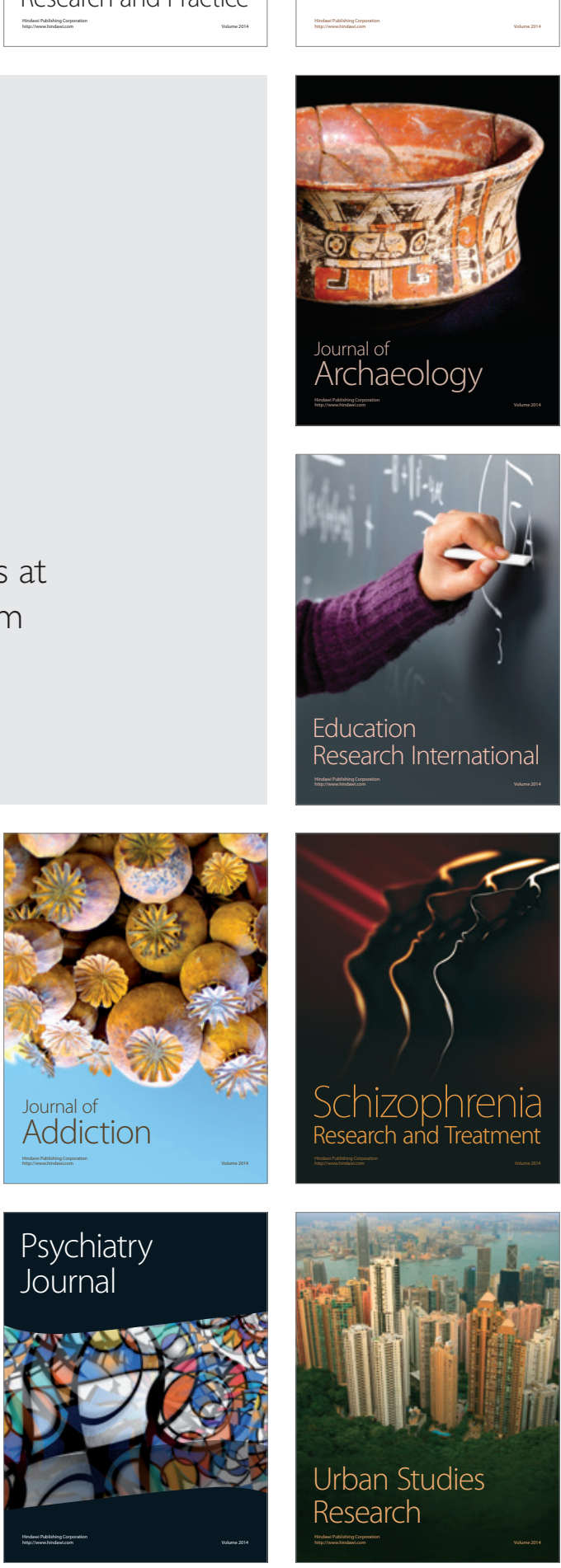